\title{
GLOBALISATION, MEDIA INFRASTRUCTURES AND IDENTITIES IN A DIASPORIC COMMUNITY CHARLES HUSBAND
}

\begin{abstract}
This paper draws upon a recently completed research project which examined the media environment and the identity politics of the Pakistani community in Bradford, England. Generation and gender were found to be powerful variables impacting upon both subjective identities and

Charles Husband is Professor of Social Analysis in the Ethnicity and Social Policy Research Unit, University of Bradford.
\end{abstract} media consumption. The relationship between subjective identities and the viability of fragmented audiences in sustaining the media infrastructure is explored: particularly through a case study of the press. The transnational nature of political agendas and media conglomerates are examined and related to the role of the public sphere in multiethnic societies. 


\section{Introduction}

This paper reports an initial analysis of data generated by a research project funded by the Economic and Social Research Council as part of a programme on Media Economics and Media Culture. This project examined the media environment of two minority ethnic communities in Britain; the Pakistani population in Bradford and the Iranian population in London. The analysis here discusses only some aspects of the data generated by self-completion questionnaires and focus group discussions with a relatively small sample of the Bradford Pakistani population; purposively sampled to reflect age and gender differences. This data is essentially qualitative in nature and is supported by ethnographic observation and a considerable body of prior relevant research (e.g., Saifullah-Khan 1976; Rex and Samad 1996; Samad 1992). Given that the project as a whole sought to explore "Islam, Globalization and the Media" it is noteworthy that even in the absence of the comparative dynamic of the project this paper amply indicates the very obvious particularity of all the interactions between the terms in that grandiose title, even when only seen through the prism of these respondents'experiences. The negotiation of personal subjectivities, collective identities and macro-processes so evident in contemporary literature (Featherstone 1995; Hannerz 1996; Radhakrishnan 1996) are evident here in the microcosm of this populations' experience.

\section{British Ethnic Relations}

In Britain, as elsewhere in Europe, the last four decades have seen a considerable migration of people and significant change in the ethnic profile of national populations (Castles and Miller 1993; Waever et al. 1993). The widespread recognition of this demographic change has in no way been paralleled by a common political response to the pragmatic necessities of managing ethnic diversity (Heckmann and Bosswick 1995; Wrench and Solomos 1993). Indeed the concept of multiculturalism, frequently invoked in discussions of ethnically diverse situations has itself no consensual meaning (Goldberg 1994). The initial complacent laissez-faire assimilationism of the British policy response to the migration and settlement of distinct ethnic minority populations was challenged in the late 1960s and through the 1970s by a liberal, but still paternalist and essentially racist, discourse of integration and cultural pluralism (Solomos 1989). Critiques of this British multiculturalism generated in the late 1980s a robust, if heterogeneous anti-racism, which was itself firmly challenged and undermined by the neo-conservatism and new racism of Thatcherite nationalism (Jessop et al. 1988; Gordon 1990). Indeed the 1990s have seen a strong and broadly based reaction to the 1980s attempt to establish a cosy acceptance of cultural pluralism backed by a strong commitment to equal opportunities. The all too evident transition in Britain"s position as a world power, paralleled by a bitter debate around European Union federalism and the de facto reality of Britain"s multi-ethnic population has produced a selfconscious renegotiation of British identity (Husband 1994). The attempt under Thatcherism to reassert English ethnicity as coterminous with British identity only exposed the fragility of the four hundred year old exercise in internal colonialism and further clarified the marginal status of Britain"s minority ethnic citizens. For importantly in Britain, unlike some other European states, the great majority of the minority ethnic populations are British citizens. They have full formal citizenship status; it is their 
fraught access to equally full substantive citizenship which has remained the basis of political tension (Brubaker 1989). The current Blairite attempt to renegotiate the political settlement within the United Kingdom through granting limited political autonomy to Wales, Scotland and now Northern Ireland has done little to reduce the neurotic anxieties of English ethnicity; and has perhaps hinted at an untheorised practice of differentiated citizenship (Kymlicka 1995) which minority ethnic citizens may wish to expose and exploit.

Britain in the late 1990s is in a general sense very considerably distanced from the complacent assimilationist sentiments and practices of the 1950s and 1960s. In education, employment and more latterly health and welfare there is official policy commitment to equal opportunities, and indeed to an unsophisticated cultural pluralism (MacEwen 1994). Blatant expressions of racism in the work place and in public services are no longer assured quiescent toleration and explicit discrimination is legally sanctioned. However, discourses that convey unambiguous racist sentiments are readily apparent in the media and in everyday life, and discrimination in employment and elsewhere continues to limit the freedoms and access to equity of minority ethnic citizens. In a country with young minority ethnic citizens whose grandparents and parents migrated and settled, and thus formed demographically distinct concentrations within the major conurbations of Britain, there is the capacity for a localised experiential sense of their marginality in Britain. Their grandparents acquiescence to exclusion is not something they are disposed to share. Minority ethnic communities are politicised by their continued exclusion, and a naive belief in melting pot Britain is not a sentiment that would have much currency among their members. Minority ethnic professionals have learned the value of organising within and through their ethnicity, community activists have learned to mobilise around negotiable ethnic labels (Anthias and YuvalDavis 1993; Husband 1996) and disenfranchised unemployed and under-employed youth have readily articulated distinct ethnic identities. Ethnicity in Britain is highly salient, and continuously negotiated in relation to racialised modes of exclusion.

\section{Negotiating Ethnicity and Identity}

It is within this context that the Pakistani population at the heart of this analysis must be placed. Attracted by the post-war demand for labour in Britain where the traditional workforce were moving toward jobs with more attractive pay and working conditions, the Pakistani migrant workers moved to specific niches in the labour market within particular locations in Britain (Rose 1969; Rex and Tomlinson 1979). Thus through a pattern of chain migration a significant Pakistani population was established around the textile industry in West Yorkshire. The majority of the Pakistani immigrants to Bradford came from Mirpur and were deeply conservative people from one of the more underdeveloped areas of rural Pakistan. As predominantly male workers arrived without their family then the mosques established in the first phase of migration and settlement were frequented irrespective of regional, sectarian or caste qualification. However, with progressive family reunification these criteria became operative as fissure took place with a segmentation of distinct membership into particular mosques. There was a consequent proliferation of mosques, Islamic schools and religio-political organisations which began to shape the internal dynamics of the Pakistani population.

Religion remains a significant aspect of the social organisation within the Pakistani community in Bradford. The many divisions within Islam are found echoed in 
Bradford. There are Shiahs and Sunni groups including the Barelvi, Deoband, Jamati-Islami, and Tabligh-i-Jamat, and Sufi orders operating in the city. Importantly these religious internal boundaries also often overlap with linguistic and religional identities. Thus, for example, a Baralvi mosque may have its management committee and Imam from a particular region and share a particular language or dialect (Samad 1998). Of equal importance is the interpenetration of religion, language, region and biraderi (patrilineal kinship groupings) which has real continuing significance in the community. Biraderi obligations continue to have an impact upon preferred marriage partners, business relations and even the Pakistani community"s participation in local and national party politics.

Notwithstanding the internal complexity of the Pakistani population its broader cohesion is facilitated by the logistics following from its demographic concentration within Bradford. Bradford Metropolitan District is the fourth largest conurbation in Britain and unlike many other major cities its population is growing; with the Pakistani population being a significant element in this process. In 1981 the population of Pakistani background numbered 34,116, and in 1991 that had risen to 38,059 persons. It is estimated that in the year 2011 this figure will be 104,000, or approximately a quarter or more of the city"s total population.

Currently the "Pakistani" population constitute over 10 per cent of the Bradford population, with 50 per cent of this minority ethnic community being under 18 years of age. This demography is further shaped by the fact that those of Pakistani background are heavily concentrated in a number of inner-city electoral wards; with 2 wards having over 50 per cent of their population of Pakistani background, and one over 70 per cent. This demography provides a spatial concentration which allows for the localised ethnic infrastructure of shops, social organisations and mosques that provide an institutional basis for the expression of a shared ethnic identity (Wallman 1986). The regional, religious and biraderi affiliations identified above are given a propitious urban geography in which family and other networks may operate. The fact that this "Pakistani" population is predominantly working class with high levels of unemployment, and with many living in areas denoted by the local authority as areas of high social stress further contributes to the internal dynamics of this population, and its relation to the dominant ethnic populations. Time seems not to be resulting in a melting pot interpenetration of dominant and minority ethnic populations, but rather if anything to increasing spatial segregation: including the emergence of areas of middle class "Pakistani" concentration extruded from the original areas of settlement.

If this "Pakistani" population is both heavily concentrated and internally differentiated it also has to a significant degree a shared history of exclusion and marginalisation from the dominant ethnic community which has including a number of specific "defining events" which have punctuated the routine of ethnocentrism, xenophobia and racism that have been part of their common experience of life in Britain, and Bradford. In recent years these have included "the Honeyford Affair," "the Rushdie Affair," the Gulf War and the riots of 1995. The Honeyford Affair was a protracted struggle over a Head Teacher who denigrated Pakistani culture and was bitterly opposed by the parents of the "Pakistani" children at his school. The process leading to his departure from the school was widely covered in the British media and was a cause célèbre in Thatcherite resistance to multicultural education. The Rushdie Affair enjoyed not only national, but international visibility as the Bradford Pakistani population were popularly 
depicted as the quintessential narrowly myopic, traditional Islamic population (Samad 1992). And the trajectory of external scrutiny and stereotyping as Muslim aliens in Christian England was further developed throughout the period of the Gulf War as representatives of the Bradford Pakistani population had to recurrently defend themselves against the proposition, put in varying degrees of vulgarity by politicians and media pundits, that it was impossible to be both Muslim and English. Thus the "Pakistani" population in Bradford have had considerable experience of being rendered self-conscious by the hostile scrutiny of the majority population. Within that scrutiny the centrality of their Muslim identity has been underlined by their majority interrogators. And in the youth riots of 1995 and its aftermath it is possible to see this religious identification in some sections of the younger population being complemented by a racialised sense of their opposition to a hostile "white" majority (Bradford Commission Report 1996).

Given this background, and this context, it is perhaps not surprising that in response to our questionnaire the majority of the respondents expressed a distinct religious affiliation; with a clear trend for religiosity to be age linked, with the older "Pakistani" respondents being more religious. There were, however, strong generational and gender linked variations within this expression of religious affiliation. Thus, of those men claiming that they were strongly religious only 33 per cent were under 25 years of age. The comparable figure for women was that of those claiming they were very religious only 16 per cent were under 25 , whereas of those claiming that they were weakly religious over 70 per cent were under 25 years of age.

It is important to be cautious in interpreting this data and to inform the analysis with the socio-cultural insights derived from the descriptive ethnography of this population; and from insights derived from the focus group data. As has already been noted this is a religiously active population and consequently even those who declare themselves to be only weakly religious, and who do not maintain all the required expressions of devout practice, may nonetheless be regarded as being much more religious than the norm by their neighbours from the majority ethnic population. Additionally, it is also conceivable that truly devout Muslims may be too modest to claim that they are very religious. Yet, despite these qualifications it remains the case that the data suggests that religiosity follows an age profile with the older members of the population being more religious than their younger counterparts.

The nature of this expression of religious affiliation and its implications for ethnic identity can be usefully further explored in the light of previous research and our qualitative data (Afshar 1994; Lewis 1994; Samad 1998). For the older members of this population their understanding of Islam is located within an oral tradition that was intimately linked to life-cycle rituals. This is a form of Islam that is steeped in rural traditions and is inevitably influenced by non-Islamic practices; theocracy and ethnicity are heavily interrelated. It is a sense of Islam that has a meaning and context within the Pakistan these older respondents left behind, rather than in contemporary Pakistan. This is a perspective on faith and identity which has patriarchal and authoritarian tendencies which importantly can have a potential powerful synergy with Northern English mores. The patriarchal and authoritarian values present within the conservative Islam reproduced in Bradford has much in common with the northern machismo of working class inner city Yorkshire (Ali 1992). Thus a common agenda regarding the role and control of women may particularly facilitate a reproduction of 
a syncretic traditional cultural version of Islam among the younger men who have been socialised both within the dominant working class culture and the particular Islamic orthodoxy of their elders. This is not a symbolic synthesis that is likely to enjoy a similar legitimacy among the younger women in this population, schooled within the dominant culture and growing up in the context of a strong feminist agenda within British youth culture.

Thus the younger generation are being partially enculturated within an oral tradition and partially their understanding of Islam is textual and derived from English language sources. It is apparent from the qualitative data that the younger respondents gravitate towards a more ecumenical Islam which glosses over the differences which have been so divisive among the older generations. Importantly the focus group data indicate that among the young women, born or brought up in Britain, their understanding of Islam differs both from that of the older generations and from their male peers. Whilst some proportion of the young men are tending to reproduce a patriarchal Islamic ethos, with a strong melding of Northern male machismo, many young women are challenging this in a number of ways. Rather than questioning Islam per se they are challenging their community"s cultural interpretation of Islam as non-Islamic; and in order to do so some are embracing a devout and informed Islamic identity all the better to exposure the alien cultural adhesions to a textual Islam (see also Afshar 1994). Thus our data shows religiosity to be complexly constructed and experienced, with significant differences in the understanding and expression of Islam along gender and generational lines.

This complexity, however, becomes both denser and richer when we examine the respondents' responses to questionnaire items asking them to indicate which of a range of collective identities they would personally identify with. Of particular interest here is the self declared identification with the labels "Pakistan" and "Muslim". Employing the category Pakistani was more prevalent among the older generation of respondents whilst the use of Muslim as an identifier was much more prevalent in the young generation, irrespective of gender. Thus, for example, of those males willing to describe themselves as "Pakistani" 29 per cent were under 25 years of age, whilst of those including themselves in the category "Muslim" 89 per cent were under 25 years of age. For the female respondents the comparable figures were; of those calling themselves "Pakistani" 11 per cent were under the age of 25 and of those calling themselves "Muslim" 53 per cent were under 25 years of age.

These findings indicate that a self defined sense of religious commitment does not in this population simply translate into an automatic use of "Muslim" as a salient self defining label. Indeed the focus group data suggests that subscribing to a Muslim identification is not necessarily synonymous with religiosity but that rather it relates to a transformation of ethnic identity within the context of Bradford, and the wider British society. Biraderi loyalties remain very real for the older generation and family obligations continue to make this a continuing diasporic reality. Endogenous marriage preferences sustain this social network with, for example, an estimated 650 spouses joining family households in Bradford, from Pakistan, per annum in recent years. Thus for the older generation Islam can be perceived as an inherent framework which is subsumed in a Pakistani identity that is itself reinforced through linguistic and clan identities. The younger generation perhaps, lack the continuity of faith, family, South Asian foundational experience and the migrant spatiality (Hesse 1993) that gives 
salience to Pakistan as the root of a Pakistani identity. Perhaps for them, finding that it is their religious identity rather than national/ethnic affiliation that most troubles the majority ethnic population, "Muslim" is an identity that has social and political credibility (Lewis 1997). As has been indicated above Islam is one of the means whereby the young generation are negotiating their gender and generational identities within the Pakistani community.

The qualitative data suggests that for the young women an identification with a Muslim identity is allowing them to invoke a devout Islamic identity which exposes the cultural accretions they perceive to have been inherited from a Pakistani territorial context, which now here in Britain are used illegitimately to limit their freedoms. Rather than challenging Islam they are asserting a textual knowledge of it and are consequently critiquing their community"s interpretation of Islam as non-Islamic. Perhaps in this process eschewing a Pakistani label may also underline the implicit British context of citizenship and identity in which a Muslim value system may be defiantly negotiated: against both the dominant Islamophobia and the community cultural conservatism. Certainly this stance also eloquently allows these young women to challenge the double standards of their brothers. For the young men marginalised in the labour market and contesting power in the community, and success outside it, with their sisters an assertion of a Muslim identity may allow for reassertion of the male ascendancy. Borrowing heavily from their community"s conservative expression of Islam, and drawing eclectically upon powerful images of militant Islam elsewhere in the world, it is possible to see how invoking a Muslim identity offers a polysemic repertoire for the young men of this community. It is apparent that young men and women are engaged in a creative hermeneutic in their use of Islam in order to negotiate their gendered and generational space. And more generally this research indicates the need for a sensitive deconstruction of the use of Muslim as a social category.

\section{Media Environment and Media Use}

On the whole, minority ethnic communities in Britain are well served by the press and the Pakistani population is no exception. Alongside daily newspapers such as the Jang and Asian Age there is a wide variety of weekly papers including the Asian Times, East and Eastern Eye; and in the context of Bradford a local press including Ravi, Awaz and Pegham. This diversity in the press provides for a range of editorial perspec-tives reflecting different generational engagement with Pakistan and South Asian politics, and differing linguistic competencies. In relation to radio in addition to the local BBC and commercial radio stations which offer modest programming targeted at minority ethnic audiences, there is Sunrise Radio which specifically targets South Asian audiences: although its success in gaining, and retaining, this license has been seen by some as a preference of Indian (Hindu) interest over a Muslim competitive bid (see Lewis 1997, 39-40). Also in Bradford there is a pirate radio station Asian Air which operates outside of the statutory inhibitions of the licensed radio stations with their delicate concerns with religious and political comment. Fast FM is a uniquely religious medium which operates under special licence and transmits prayer and religious material during the month of Ramadan. Radio then, like the press, is able to offer a range of contents which address different audience appetites. Nor are the visual media excluded from this ethnically focused activity. The local cable television operator offers Asia Net and Zee TV, whilst Bollywood films and Urdu dramas are easily available for rental from 
the plethora of small video rental shops scattered through the denser areas of Pakistani residence in the city. And recently the demise of the Asian cinema in Bradford, following upon the ubiquitous impact of video cassette recorders, has been partially corrected by new release Bollywood movies being shown in regular special screenings at a main distributor "Odeon" and an "art house cinema" in Bradford.

The size of this "Pakistani" population and its concentrated urban demography serve to create a physical environment in which they constitute a financially viable market for a range of appropriate media. Consequently the media environment of this community offers a rich infrastructure of media that provide a range of entertainment and information capable of addressing a range of appetites within the Pakistani population defined by generation, gender, political affiliation and linguistic competence. Expressed in a different way, the richness of this media environment allows for a considerable degree of audience fragmentation and facilitates the reproduction of distinct "hybrid" identities within the Pakistani population (Werbner and Modood 1997).

Analysis of the questionnaire data indicated that age and gender were clearly significant in shaping patterns of media use. Consumption of the "mainstream" majority ethnic media was widespread throughout the sample, with the younger respondents consuming more of this mainstream broadcast and print media that the older generations. The linguistic barriers which lock some of the older generation into Asian language media such as video, television and the minority language press equally served to deter the younger respondents from using them as extensively. Younger members of the community may not be literate in the community language, and indeed as the focus groups revealed, may also on occasions be more comfortable in spoken English.

This linguistic filter appears to be a major determinant of the revealed pattern of media use. Thus, for example, in relation to the minority ethnic press the readership of the Jang, published predominantly in Urdu, is skewed toward the older generation, whilst the readership of the English language Eastern Eye has a much younger profile within our sample.

Language of course is not the only variable determining media use. Within a diasporic community it was apparent that current events in Pakistan were a more salient issue for the older generation and consequently it is not surprising that the Jang, with its concern with current events in the Indian sub-continent, has a stronger appeal among the older generation. Whereas Eastern Eye, with a focus on Britain and Europe, attracted a much younger readership. Nor was an orientation to current affairs the only non-linguistic factor. In a way which would be consistent with Gillespie"s (1995) findings, a culturally driven generational sensibility toward the moral propriety of media content was also clearly apparent within the data and this too was a determining force in media use.

\section{Press Case Studies - Glocalised Audiences and Transnational Media}

Migrants and refugees have a great need of information about both their country of departure and their country of settlement (Husband 1988), and certainly the emerging Pakistani communities in Britain were revealed by Qaisrani (1990) as having exactly such needs. His account of the development of the Urdu press in Britain provides a clear testimony of the need for information from "home" and of the related 
need for a vehicle to provide a conduit for information across the dispersed Pakistani population in Britain in the 1960s and 1970s. Indeed writing of the Urdu press in Britain in the 1980s he notes that: "Stories from and about Pakistan form the bulk of the coverage of the Urdu newspapers even today and they virtually look like an extension of the Pakistani press" (Qaisrani 1990, 53). Certainly for the older generation within the Pakistani communities in Britain this first informational need is still apparent; and as we shall see below is reflected in the current editorial policies of the Jang.

The argument below draws upon interviews carried out with the editorial staff of the South Asian press in Britain in autumn 1997. This material can only be dipped into here to illustrate the dense interaction of the subjective identities reflecting particular locations in a diasporic experience heavily shaped by generation and gender, and the logistics of media economics. Subjectively fragmented "audiences" are differentially viable as markets and the corporate strategies of media groups privilege some identity options over others.

\section{The Jang}

Pakistani migrants in coming to the UK needed to have information about home; and initially this need was underpinned by the belief that they would be returning home (Anwar 1979). However, over time, and particularly after the 1968 Immigration Act, it became clear that that was not going to take place for the majority of economic migrants whose initial pattern of cyclical migration had been blocked by the increasingly draconian immigration policy. The Jang came to meet this need and its first international edition produced from London was published in March 1971. As Qaisrani $(1990,41)$, noted the Jang in its early days had some advantages over its competitors: not least of which was the fact that in the 1970s it had an established name with which many in the Pakistani community were already acquainted. Additionally it had a direct link with a major newspaper group in Pakistani.

At that time the logistics of publishing a newspaper essentially based upon the Pakistani edition was difficult since among other things it was necessary to book a telephone call to Pakistan. There was a heavy reliance upon the teleprinter. At that time the newspapers were sent from Pakistan by plane and consequently the news was often three days late for the British readers. From the early 1980s the British edition of the Jang started to move from being a source of information about events in Pakistan and began to additionally cover local community news within the British Pakistani communities. This has resulted in the Jang now having stringers throughout Britain and in Europe. And consequently their readers now look to the Jang for a much wider range of news than would have been the case throughout its first decade of operation.

The current status of the Jang has been described by a senior executive as being a serious family paper with a strong appeal to the older and professional segments of the Pakistani communities in Britain who have a clear preference for hard news. The editor is aware that there is a competing demand for a more popular tabloid style journalism among younger readers. (And this is clearly being addressed by other papers such as Eastern Eye and East.) As the age profile of the Pakistani communities have changed over the years so too the proportion of the available readership who are literate in Urdu has changed; with many of the younger generation often not being functionally literate in Urdu even though they may be able to speak it. Thus approximately three years ago the Jang introduced an English language section which 
is now routinely produced as four pages in English and eight pages in Urdu. The editorial staff see the Jang as a family paper which goes into the home and has a substantial secondary readership. Thus although direct sales may be only about 25,000 it is argued that its effective readership may be as high as 300,000 . This is of course an assertion that has no empirical support.

However, the British circulation of the Jang is very small when compared to the size of its circulation in Pakistan and, as we shall see when examining its British operation, the British edition derives enormous benefits from being part of a large newspaper group. The production costs of the London based international edition are reduced dramatically by a number of factors both journalistic and technological. At the level of news production the London edition derives the great part of its coverage of events in Pakistan and the sub-continent directly from the Pakistani edition. There are, however, some interesting constraints operating upon this process. Thus, in recent years the press in Pakistan has enjoyed considerable deregulation and operates with considerable freedom in offering sensational journalism that would not be acceptable in Britain. At one level the more severe British libel laws mean that stories published in Pakistan might well be actionable if published in Britain; and must therefore be judiciously edited. Secondly the appetite for salacious stories amongst some of the readership of the Jang in Pakistan is not matched by the British readership, with its bias toward older members of the British Pakistani communities, and therefore a degree of editorial discretion is required to avoid offending their British readership. In fact within the Jang Group of newspapers it is a general policy that whilst there is a broad editorial perspective common over all the sites, local editors do have a perspective attuned to the local context. In the case of London this is particularly to Britain, and to Europe; with the London edition producing four pages of news on the United Kingdom and Europe and more generally reflecting the sensibilities of their readers. However, notwithstanding this necessary editorial intervention the news gathering costs of the London international edition of the Jang must be extensively reduced by their ability to draw heavily upon copy generated by the parent paper in Pakistan.

Technology also provides a means of generating economic synergies between the papers in Britain and Pakistan. The days of booking telephone calls are long gone and satellite technology and modern information technology has offered a fast and efficient communicative system between Pakistan and London which facilitates both news gathering and production. Thus, for example, the design work and colour production for the London Jang is done in Karachi. Copy is compiled and edited in London transmitted to Karachi where the design work is carried out and the finished product is then transmitted back to London for printing and distribution.

Thus the Jang represents a newspaper that has an established position within the media environment of the British "Pakistani" population. Its structural location within a Pakistan based press group meshes well with its own news values in relation to its British readership. Retaining something of the original ethos of linking a diasporic community to its rooted identity in their country of emigration the Jang has a particular niche in the generationally shaped news audience within the British Pakistani population.

\section{The Asian Times/Eastern Eye}

Both the Asian Times and Eastern Eye are produced by the same organisation, from the same site and sharing the same staff; and these weekly papers provide a clear 
example of complementary products serving demarcated audiences from a highly cost effective production base. There is a clear distinction between the intended audience of the two papers. Asian Times is regarded as being targeted at the first and second generation within the Pakistani communities, whilst Eastern Eye is seen as appealing to the younger generation located in the second and third generations. And it was suggested that the readership of Eastern Eye has a lower class profile than that of the Asian Times. As an editorial corollary of this, the Asian Times is seen as a campaigning, information driven paper of report, whereas Eastern Eye is much more entertainment oriented. To paraphrase a member of staff — "Asian Times readers are very pernickety about sub-continental politics whereas Eastern Eye readers are young people engaged in inter- and intra-ethnic conflict in the British context." And despite the entertainment orientation of Eastern Eye the same member of staff noted that in relation to this conflict "We have to report it ... it has to be given a moralistic message." So whilst these two papers have distinctly different target audiences it would be wrong to polarise them as "news" versus "showbiz-enertainment" products.

A further editorial distinction made in profiling the two sister newspaper is defined through the deliberate construction of preferred identifies for the readership of each. Eastern Eye in addressing the broad range of interests of a younger, significantly British born audience, quite deliberately prefers to promote and utilise the term "Asian." This generic collective noun seeks to construct an audience which transcends national identities rooted in the India sub-continent. Thus subjects of stories will be identified by their personal names, rather than through the use of national or ethnic labels. In contrast in the Asian Times events may be described through such identifiers as Bangladeshi, Pakistani or Indian. Thus the two papers reflect, and construct, different conceptions of minority ethnic identity formation. A member of the editorial staff spoke of Eastern Eye as addressing a "hybrid audience" and of their attempt to down play religion as an issue in either paper. Consequently for the younger generations the invocation of a collective "Asian" identity may be seen as both a marketing strategy likely to maximise the potential readership; and as a vehicle for subordinating interethnic and national differences and tensions within their reportage. There was an explicitly stated concern to be very self conscious in "getting the balance right" in reporting. Interestingly, however, it seems that for the older readership of Asian Times it is not thought possible to detach them from their routine use of national/ethnic labels in their construction of, and understanding of, their world.

Producing two complementary newspapers within the same production group clearly provides significant economies of scale and the clear editorial distinction between the distinctly different readership of the two papers facilitates a double exploitation of common news material. Indeed further economies arose from the significant use of news from the wire service rather than an extensive journalistic staff. These papers like all those interviewed demonstrated an ability to compensate for finite markets by a rigorous control of production costs. This has been all the more important in an ethnic minority press sector which has not been able to attract the level of advertising revenue that has typically been available to the mainstream press: although in recent years minority ethnic business enterprises have developed a stronger advertising culture. Additionally, agencies like Media Reach, operating as a specialist advertising agency targeting minority ethnic audiences, have begun to successfully educate Government agencies that minority ethnic audiences must be specially targeted; and have educated specific manufacturers to understand that within 
the ethnic minority communities there are segments of significant wealth with specific consumer tastes. At present, however, advertising revenue has to be hard fought for within the minority ethnic press in Britain.

\section{Ravi}

An example of the other end of the scale of newspaper production for the Pakistani population in Bradford is to be found in Ravi. This weekly paper is produced and printed in Bradford and is virtually a family product. The editor, who describes himself as "a self-taught journalist" has a strong literary agenda which reflects his own interest as an author of short stories. This commitment to addressing a literate audience goes beyond merely an expectation of literacy in Urdu among his readership, but also an assumption of a common commitment to a world of letters. In Ravi discussion of Indian and Pakistani politics is matched by a strong literary content. Not surprisingly perhaps this paper has a small circulation and like minority ethnic newspapers elsewhere in the world is dependent upon the personal commitment of those producing it for its survival.

Although it is able to attract limited advertising from some local businesses its main source of revenue is through annual subscription. Ravi has survived for over twenty years, and though produced from very modest business accommodation by the editor, his wife, and daughter, it has a resilience that must be at risk in the face of the changing generational and linguistic profile of the Pakistani community. In a telling comment the editor observed that his aspiration had been that Ravi might be "the voice of the community" but that in reality the very heterogeneous nature of "the community" had made this unrealisable. Compared to the other papers mentioned here Ravi is insignificant in market terms, and yet for some members of the Pakistan population in Britain it remains a valued and continuing part of their media environment: a particular and minority voice which perhaps reminds us that when labour is not fully costed personal commitment and satisfaction can go a surprising way toward defying industry economic logics.

\section{Discussion}

An important feature of the minority ethnic press reporting for, and on, the Pakistanis' community in Britain is the translocation of Pakistani party politics to the Pakistani communities in Britain. This domestication of Pakistani sub-continental politics in the British context blurs any easy distinction between British and overseas news. Events in Britain are not irrelevant to the political process in Pakistan, and political agendas fiercely contested in Pakistan, are not without organised factional support in Britain. Thus one editor spoke of being aware of the significance of such party political mobilisation within Britain, and actively feeling its impact upon editorial decisions in attaching priority to certain events in Britain precisely because they lay on this intersection of sub-continental and British Pakistani community politics. Such events have transnational relevance and their salience in the British context is highlighted by the presence of organised political activity, rather than merely general political interest within the readership, in Britain.

The presence of this transnational political agenda within the British context and its coverage in the community press suggests that different generations within the Pakistani communities in Britain may engage with this copy and these issues from quite different existential perspectives. For example, for those who personally remem- 
ber partition the politics of MQM may be expected to evoke somewhat different connotations than may be elicited in British born young adults. And similarly the struggles around Kashmiri independence or the partisan politics of Hisb-ut-Tahir will have quite different experiential relevance for readers with differing personal contact with subcontinental politics.

As we have seen above the negotiation of identities across gender and generational divides is shaping a diverse range of subjectivities which seek to exploit the surrounding media environment in highly selective ways. The evidence of this study suggests that the richness of the media environment is allowing for considerable audience segmentation. A recognition of the complex cultural and psychological geography of diasporic communities such as the one studied here (Brah 1996; Modood and Werbner 1997), provides a framework for contextualising the differentiated media usage revealed above. And, as the press case studies reveal globalisation occurs not only as globability, a state of conscious connectedness (Robertson 1992), but as a transnational economic and production network. Nor, as the experience of Ravi reminds us, is the local entirely eclipsed by the global? The socioscapes (Albrow 1997) consequent upon migration and the particular demography of settlement mesh with an internationalised mediascape and econoscape (Appadurai 1990) to produce a fast changing and increasingly sophisticated media environment. The current identity politics of minority ethnic community boundary construction and the demographic trajectory of communities like the one studied here seem likely to ensure a vital and diverse minority ethnic media system in Britain into the foreseeable future.

However this optimism must be qualified by a reasonable anxiety that arises precisely from the extension of consumer choice and the viability of minority ethnic media sketched above. Doubtless digitalisation, cross subsidisation within media conglomerates and the changing demography of minority ethnic communities will generate both the demise of some existing media and the innovative emergence of others. The general trajectory is likely to be a greater opportunity for minority ethnic consumers to select a communication environment consistent with their own identity and interests. There will of course be a comparable media environment for the majority ethnic community. This market fragmentation is not necessarily consistent with the promotion of a public sphere capable of facilitating a viable and vital democratic dialogue within a multiethnic society. Given the centripetal politics of ethnic mobilisation that can be traced within contemporary ethnic identity politics (Taylor 1992) then the emergence of multiple ethnically bounded mediascapes is more consistent with a Tower of Babel facilitated by parallel public spheres operating in practised ignorance of each other. A viable multi-ethnic public sphere (Husband, 1996b and forthcoming) requires both a media infrastructure that can address and reflect the interests of specific ethnic communities, and media which facilitate dialogue and engagement across ethnic boundaries.

In Britain at present the dominance of the majority ethnic voice within mainstream media remains apparent; although subject to exposure and attack. At the same time, as the experience of the Pakistani community in Bradford has indicated, within the wider media infrastructure the diversity of identities within ethnic minority communities are now being targeted, and facilitated, by the media. Just as the tensions between uniquely complex ethnic identities and a shared common citizenship are being worked out in a range of political scenarios, so too is this tension likely to become apparent in the emerging media structures. 


\section{Note:}

This research was funded as a project within the ESRC Research Program on Media Economics and Media Culture. The project team were Professor Charles Husband and Dr. Yunas Samad (ESPR), Professor Annabelle Sreberny, Centre for Mass Communication Research, University of Leicester, and Mr. Adam Sabondchian, CMCR.

\section{References:}

Afshar, Haleh. 1994. Muslim Women in West Yorkshire: Growing up with Real and Imaginary Values Amidst Conflicting Views of Self and Society. In H. Afshar and M. Maynard (eds.), The Dynamics of "Race" and Gender, 127-147. London: Taylor and Francis.

Albrow, Martin. 1997. Travelling Beyond Local Cultures: Socioscapes in a Global City. In J. Eade (ed.), Living in the Global City, 37-55. London: Routledge.

Ali, Yasmin. 1992. Muslim Women and the Politics of Ethnicity and Culture in Northern England. In G. Sahgal and N. Yuval-Davis (eds.), Refusing Holy Orders: Women and Fundamentalism in Britain, 101-123. London: Virago.

Anthias, Floya and Nira Yuval-Davis. 1993. Racialized Boundaries. London: Routledge.

Anwar, Muhammed. 1979. The Myth of Return: Pakistanis in Britain. London: Heinemann.

Appadurai, Arjun. 1990. Disjuncture and Difference in the Global Cultural Economy. Theory, Culture and Society 7, 295-310.

Brah, Avtar. 1996. Cartographies of Displacement. London: Routledge.

Brubaker, William Rogers. 1989. Immigration and the Politics of Citizenship in Europe and North America. New York: University Press of America.

Castles, Stephen and Mark J. Miller. 1993. The Age of Migration. Basingstoke: Macmillan.

Featherstone, Mike. 1995. Undoing Culture. London: Sage.

Gillespie, Marie. 1995. Television, Ethnicity and Cultural Change. London: Routledge.

Goldberg, David Theo. 1994. Multiculturalism: A Critical Reader. Oxford: Blackwell.

Gordon, Paul. 1990. A Dirty War: The New Right and Local Authority Anti-racism. In W. Ball and J. Solomos (eds.), Race and Local Politics, 145-190. London: Macmillan.

Hannerz, Ulf. 1996. Transnational Connections. London: Routledge.

Heckmann, Friedrich and Wolfgang Bosswick. 1995. Migration Policies: A Comparative Perspective. Stuttgart: Enke.

Husband, Charles. 1988. The Media and Refugees: Communication and Human Rights in the Refugees" World. In T. Hujanen (ed.), Information, Communication and the Human Rights of Migrants, 153-190. Lausanne: Bureau Lausannois Pour Les Immigres.

Husband, Charles. 1994. "Race" and Nation: The British Experience. Perth, WA: Paradigm Press.

Husband, Charles. 1996. Defining and Containing Diversity: Community, Ethnicity and Citizenship. In W. I. U. Ahmad and K. Atkin (eds.), "Race" and Community Care, 29-48. Buckingham: Open University Press.

Husband, Charles. 1996b. The Right to the Understood: Conceiving the Multi-Ethnic Public Sphere. Innovation 9, 2, 205-216.

Husband, Charles. Forthcoming. Differentiated Citizenship and the Multi-ethnic Public Sphere. The Journal of International Communication.

Jessup, Bob, Kevin Bonnett, Simon Bromley, and Tom Ling. 1988. Thatcherism. Cambridge: Polity Press.

Kymlicka, Will. 1995. Multicultural Citizenship. Oxford: Clarendon.

Lewis, Philip. 1994. Islamic Britain. London: I. B. Tauris.

Lewis, Philip. 1997. Arenas of Ethnic Negotiation: Cooperation and Conflict in Bradford. In T. Modood and P. Werbner (eds.), The Politics of Multiculturalism in the New Europe. 126-146. London: Zed Books.

MacEwen, Martin. 1994. Anti-Discrimination Law in Great Britain. New Community 2, 3, 353-370.

Modood, Tariq and Pnina Werbner, eds. 1997. The Politics of Multiculturalism in the New Europe. London: Zed Books. 
Qaisrani, Safid Mansoor. 1990. Urdu Press in Britain. Islamabad: Mashal Publications.

Radhakrishnan, Rafagopalan. 1996. Diasporic Mediations. Minneapolis: University of Minnesota Press.

Rex, John and Yunas Samad. 1996. Multiculturalism and Political Integration in Birmingham and Bradford. Innovation 9, 1, 11-31.

Rex, John and Sally Tomlinson. 1979. Colonial Immigrants in a British City. London: Routledge and Kegan Paul.

Robertson, Roland. 1992. Globalization. London: Sage.

Rose, Eliot Joseph Benn. 1969. Colour and Citizenship. Oxford: Oxford University Press.

Saifullah-Khan, Verity. 1976. Pakistanis in Britain: Perceptions of a Population. New Community 5, 3, 222-9.

Samad, Yunas. 1992. Book Burning and Race Relations: Political Mobilisation. New Community 18, 4, 507-519.

Samad, Yunas. 1998. Multiculturalism, Muslims and the Media: Pakistanis in Bradford. Working paper. ESPR Bradford University.

Solomos, John. 1989. Race and Racism in Contemporary Britain. Basingstoke: Macmillan.

Taylor, Charles. 1992. Multiculturalism and "The Politics of Recognition." Princeton: Princeton University Press.

The Bradford Commission Report. 1996. The Report of an Inquiry into the Wider Implications of Public Disorders in Bradford. London: The Stationery Office.

Waever, Ole, Barry Buzan, Morten Kelstrup, and Pierre Lemaitre. 1993. Identity, Migration and the New Security Agenda in Europe. London: Pinter.

Wallman, Sandra. 1986. Ethnicity and the Boundary Process in Context. In J. Rex and D. Mason (eds.), Theories of Race and Ethnic Relations. Cambridge: Cambridge University Press.

Werbner, Pnina and Tariq Modood. 1997. Debating Cultural Hybridity. London: Zed Books.

Wrench, John and John Solomos. 1993. Racism and Migration in Western Europe. Oxford: Berg. 